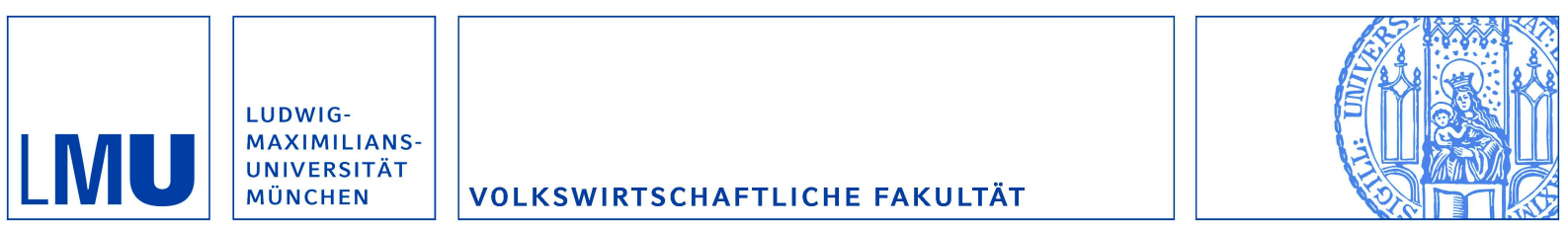

Böninghausen, Benjamin und Zabel, Michael:

Credit Ratings and Cross-Border Bond Market Spillovers

Munich Discussion Paper No. 2013-33

Department of Economics

University of Munich

Volkswirtschaftliche Fakultät

Ludwig-Maximilians-Universität München

Online at https://doi.org/10.5282/ubm/epub.21075 


\title{
Credit Ratings and Cross-Border Bond Market Spillovers*
}

\author{
Benjamin Böninghausen ${ }^{\dagger} \quad$ Michael Zabel $^{\ddagger}$
}

September 10, 2013

\begin{abstract}
This paper studies spillovers across sovereign debt markets in the wake of sovereign rating changes. We compile an extensive dataset covering all announcements by the three major agencies (Standard \& Poor's, Moody's, Fitch) and daily sovereign bond market movements of up to 73 developed and emerging countries between 1994 and 2011. To cleanly identify the existence of spillover effects, we perform an explicit counterfactual analysis which pits bond market reactions to small revisions in ratings against reactions to all other, more major changes. We also control for the environment in which an announcement is made, such as the anticipation through watchlistings and the interaction of similar rating actions by different agencies. While there is strong evidence of negative spillover effects in response to downgrades, positive spillovers from upgrades are much more limited at best. Furthermore, negative spillover effects are more pronounced for countries within the same region. Strikingly, this cannot be explained by fundamental linkages and similarities between countries.
\end{abstract}

JEL classification: G15, F36

Keywords: Sovereign debt market, credit rating agencies, cross-border spillover effects, international financial integration

\footnotetext{
${ }^{*}$ We are grateful for valuable comments and suggestions by Gerhard Illing, Monika Schnitzer and Christoph Trebesch as well as seminar participants at LMU Munich, the $27^{\text {th }}$ Irish Economic Association Annual Conference in Maynooth, the 2013 EDGE Jamboree at the University of Cambridge, and the 2013 Annual Congress of the Verein für Socialpolitik in Düsseldorf. Benjamin Böninghausen gratefully acknowledges financial support from the Deutsche Forschungsgemeinschaft through GRK 801.

${ }^{\dagger}$ Munich Graduate School of Economics, Kaulbachstraße 45, 80539 Munich, Germany. E-Mail: benjamin.boeninghausen@lrz.uni-muenchen.de

$\ddagger$ University of Munich, Seminar for Macroeconomics, Ludwigstraße 28 (rear building), 80539 Munich, Germany. E-Mail: michael.zabel@lrz.uni-muenchen.de
} 


\section{Introduction}

Ever since tensions began to surface in the eurozone in late 2009, the announcements by credit rating agencies (CRAs) on the creditworthiness of member states have continuously made the headlines and rattled financial markets. In particular, while not specific to the ongoing crisis, the notion that rating actions pertaining to one country might have a major impact on the yields of other countries' sovereign bonds, too, has regained the attention of policymakers. In fact, concerns over so-called negative spillover effects have been running so deep that the European Commission was at one stage considering a temporary restriction on the issuance of ratings under exceptional circumstances (Financial Times, 2011). This provides the background for why the Commission has just recently set up stricter rules for the agencies. In particular, CRAs are now only allowed to issue three ratings for EU member states' sovereign debt at pre-defined dates every year (European Union, 2013).

These considerations carry two major assumptions on the behaviour of sovereign bond markets in the wake of rating announcements. The first assumption is that, when a rating announcement is made for one country, there exist significant spillover effects on other countries' sovereign bond markets. Conditional on their existence, the second assumption posits that such spillovers must, in one way or another, be unwarranted to merit an intervention by the state. In more technical terms, it suggests that spillovers are unrelated to economic fundamentals. While both assumptions are highly policy relevant and therefore deserve close scrutiny, they are not straightforward to test.

This paper sets out to cleanly identify the existence of cross-border spillover effects of sovereign rating announcements, and to establish the economic conditions under which those effects are strongest, or which countries are affected most. To this end, we collect an extensive dataset which comprises a complete history of both the sovereign rating actions by the "Big Three" (Standard \& Poor's, Moody's, and Fitch) and daily sovereign bond market movements for up to 73 countries between 1994 and 2011. The dataset contains substantial variation as it covers both crisis and non-crisis periods as well as a broad set of developed and emerging countries across all continents. 
Crucially, the variation allows us to pursue a novel empirical strategy to identify potential spillover effects. More precisely, we perform an explicit counterfactual analysis which pits bond market reactions to small revisions in an agency's assessment of a country's creditworthiness against bond market reactions to all other, more major changes. This not only helps us get around the problems associated with a classic event-study approach in a spillover context. It also does not require the additional assumptions made by a number of papers.

A traditional event-study procedure, where bond market movements in an estimation window serve as the counterfactual for bond market reactions in an event window, is suitable in principle but, in a spillover context, places too high demands on the necessary noncontamination of the estimation window. This is because, if one entertains the possibility of cross-border spillovers after rating announcements, each country's bond yields are potentially affected by any sovereign rating change in the world. The estimation window can therefore only be considered uncontaminated if no such change has occurred anywhere. As the number of instances where this can be ensured is extremely low, the classic event-study approach appears ill-suited to thoroughly identify spillover effects. Hence, in this paper, we focus on a pooled cross section of short event windows, in which small changes of the actual rating serve as the counterfactual for larger changes.

While some papers also investigate spillovers in a pooled cross section framework, their analyses do not postulate an explicit counterfactual, as we do. ${ }^{1}$ Instead, they rely on a "comprehensive credit rating" which combines two different types of rating announcements - actual rating changes and watch, or review, changes - into a single scale. Their identification therefore depends on rather strong additional assumptions on the relative informational content of reviews and ratings. We, however, focus solely on the class of actual rating changes. In detail, we test whether a country's sovereign bonds react more heavily to upgrades or downgrades elsewhere when those are "large" - ie, when the actual rating changes by two notches or more. The group of "small" one-notch changes serves as the counterfactual during that exercise. At the same time, we explicitly allow for differences in the informational content of sovereign rating changes by controlling for watchlistings that

\footnotetext{
${ }^{1}$ See Afonso et al. (2012), Alsakka and ap Gwilym (2012), Gande and Parsley (2005), and Ismailescu and Kazemi (2010).
} 
may build anticipation in the market. Moreover, we are also able to account for the fact that an announcement is often followed by a similar one from a different agency soon after, which may further influence the reception of the later announcements. ${ }^{2}$

Our findings on the existence of cross-border spillover effects point to an important asymmetry in the sovereign debt market's treatment of ratings. On the one hand, we find significant spillovers in the wake of sovereign rating downgrades, which turn out to be robust to a number of tests. On the other hand, reactions to upgrades appear to be much more muted, if anything.

We then investigate to what extent spillovers are driven by country characteristics. Importantly, we find that spillovers from downgrades tend to be significantly more pronounced for countries within the same region. We proceed by testing whether this can be explained by bilateral trade linkages, financial integration or fundamental similarities between countries. However, even after controlling for these factors, we still find that belonging to a common region amplifies cross-border spillover effects. Hence, our findings suggest that policymakers' concerns over some countries being found "guilty by association" cannot be easily dismissed. Our paper is related to a broad strand of literature that investigates the effects of sovereign rating announcements on different segments of the financial markets. The most common exercise is to conduct an event study gauging the direct impact of rating changes on the bonds issued by the country concerned. However, there is also a substantial body of research analysing the reaction of the country's stock and, more recently, of its CDS market. As a general result, this literature finds a strong and significant impact of sovereign rating downgrades, while upgrades have an insignificant or more limited impact (see, eg, Cantor and Packer, 1996; Larraín et al., 1997; Reisen and von Maltzan, 1999; Brooks et al., 2004; Hooper et al., 2008; Hill and Faff, 2010).

Moreover, in recent years a growing body of research has specifically studied whether sovereign rating changes also lead to spillover effects on other countries' sovereign bonds. Generally speaking, the literature affirms the existence of such spillovers, meaning that a rating action on one country is found to significantly affect the sovereign bond prices of other

\footnotetext{
${ }^{2}$ To the best of our knowledge, we are the first to consider such interactions between the major CRAs in identifying spillover effects.
} 
countries (eg, Arezki et al., 2011; De Santis, 2012; Ismailescu and Kazemi, 2010). Some studies also point out that spillovers are not limited to sovereign debt markets but that rating changes also affect foreign stock and exchange markets (Kaminsky and Schmukler, 2002; Arezki et al., 2011; Alsakka and ap Gwilym, 2012). Regarding a potential asymmetry in the spillover effects of negative and positive rating events, the results of the literature so far remain inconclusive. Whereas Afonso et al. (2012) find spillovers to matter most for downgrades, with little or no effects of sovereign upgrades, Ismailescu and Kazemi (2010) find positive rating events to have a greater spillover effect on foreign CDS prices than negative ones.

With the exception of Gande and Parsley (2005), these studies focus either on spillover effects during specific regional crisis episodes ${ }^{3}$ or on an otherwise homogeneous sample of countries only, such as emerging countries (Ismailescu and Kazemi, 2010; Kaminsky and Schmukler, 2002). In addition to some of the shortcomings already mentioned above, this leaves open the question to what extent their findings are of more general relevance.

The paper is organised as follows. In the next section, we describe the dataset and highlight some important characteristics of rating announcements. Section 3 discusses the estimation strategy for identifying cross-border spillovers. Section 4 presents our empirical results and discusses their interpretation. We end with a brief conclusion.

\section{Data}

\subsection{The dataset}

For our study, we compile a broad dataset of the yields of publicly traded sovereign bonds at daily frequency. The dataset starts in January 1994 and ends in December 2011. Whereas our dataset only comprises sovereign bonds issued by 27 countries in 1994, this number increases to 74 countries towards the end of our sample period. This reflects both the increased financing needs of sovereigns and the growing prevalence of bond issuance, as

\footnotetext{
${ }^{3}$ See Afonso et al. (2012), Arezki et al. (2011), and De Santis (2012) for the eurozone crisis, Kaminsky and Schmukler (1999) for the 1997/98 Asian crisis.
} 
Figure 1: Number of sovereign bonds in dataset

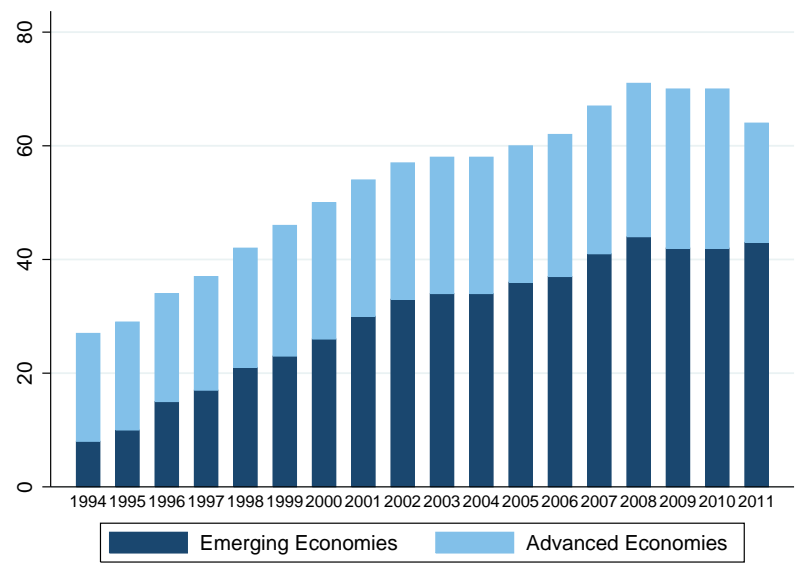

Notes — This figure shows the scope and composition, by economic development, of the sovereign bond sample between 1994 and 2011, highlighting a notable increase in the coverage of emerging economies over time. Countries are classified according to the IMF World Economic Outlook.

opposed to bank financing, during the last 20 years. While for 1994 sovereign bond yields are mostly available for developed countries, the availability of emerging market bond yields picks up heavily over our sample period. Towards the end of the period, emerging markets even account for the bulk of sovereign bonds in the sample. Figure 1 illustrates the increasing scope of our dataset over time.

In order to consider a broad spectrum of sovereign bonds, our sample draws on data from different sources. Our preferred data source is Bloomberg, from which we use generic 10-year yields for up to 33 countries. If data are not available on Bloomberg, we supplement them with yields from Datastream's 10-year Government Bond Benchmark Index. We also use data from the JP Morgan Emerging Markets Bond Index Global (henceforth EMBI Global, see JP Morgan, 1999). ${ }^{4}$

For the purpose of our later analysis, we compute sovereign bond spreads. The spread is the differential of the country's sovereign bond yield over that of a US Treasury bond of comparable maturity. We use 10-year maturities where possible, which is the case for the developed economies and some emerging markets. For the other emerging economies, we rely on the EMBI Global data. As those correspond to different maturities, we obtain the relevant US Treasury yields by interpolating from the closest published yield curve rates.

\footnotetext{
${ }^{4}$ While bonds included in the EMBI Global have to fulfil strict requirements regarding the availability of reliable daily prices, the average maturity of a country's bond index can vary remarkably from that of the other two sources. We therefore control for maturity in all regressions.
} 
Figure 2: Number of rated countries

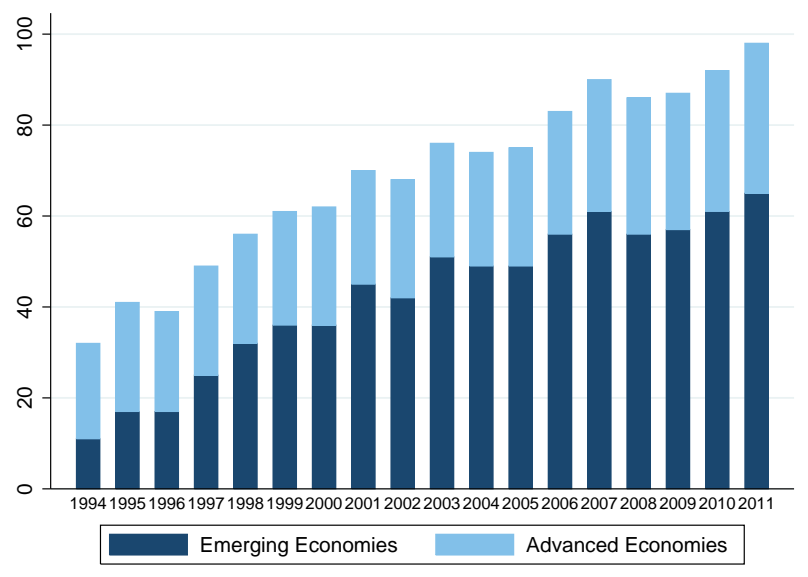

Notes — This figure shows the scope and composition, by economic development, of the sample of countries rated by at least one of the major rating agencies (S\&P, Moody's, Fitch) between 1994 and 2011, with a notable increase in the coverage of emerging economies over time. Countries are classified according to the IMF World Economic Outlook.

Information on sovereign ratings comes from the rating agencies' websites and includes daily information both on rating changes and on sovereign watchlistings by any of the "Big Three" (S\&P, Moody's, Fitch) from 1994 to 2011. Like the number of publicly traded sovereign bonds, the scope and composition of countries rated by the "Big Three" changes quite substantially during our sample period. While in 1994 only 34 sovereigns were rated by at least one of the agencies, this number had increased to 98 countries by 2011 (see Figure 2).

\subsection{Characteristics of rating announcements}

Over the whole sample period, we are able to consider a total of 1,097 rating changes, of which 635 were upgrades and 462 downgrades. In general, one can observe a significant increase in the number of sovereign credit ratings during our sample period, particularly in emerging market countries.

As Figure 3 illustrates, rating activity is not evenly distributed over time but, especially for downgrades, shows some hefty peaks during specific episodes of crisis. Whereas in "normal times", downgrades tend to be relatively scarce, a severe increase can be observed in the context of the 1997/98 Asian crisis (affecting mostly emerging countries plus South Korea and Hong Kong) and following the 2008-2011 financial and European debt crises (where 
Figure 3: Rating actions over time
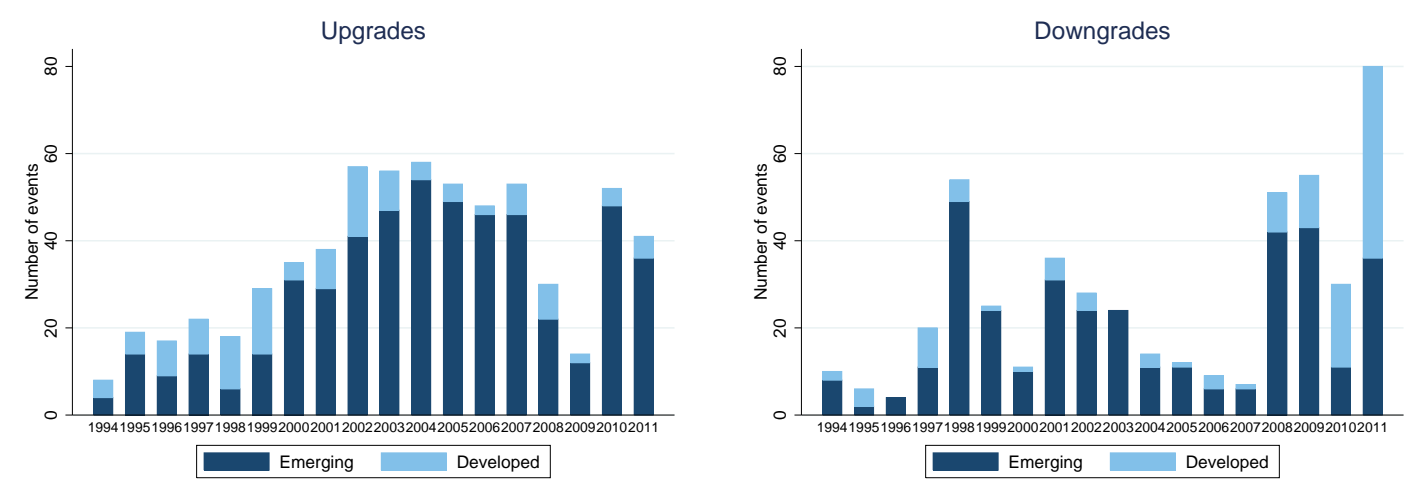

Notes - This figure shows upgrades and downgrades of developed and emerging economies made by S\&P, Moody's and Fitch between 1994 and 2011. Countries are classified according to the IMF World Economic Outlook.

for the first time advanced economies were exposed to downgrades at a large scale). This means that similar announcements tend to cluster around certain time periods.

In addition, it is an important stylised fact that the downgrading of a country is frequently followed by yet another downgrade announcement for that same country soon after. This is all the more probable because there is a strong overlap in country coverage by the "Big Three". Almost all countries in our sample are rated by more than one agency only and most are even rated by all three (70 out of 98 countries at the end of 2011). Hence, in what we term within-clustering, different agencies may make the same announcement for a given country in short succession or even on the same day. Figure 4 illustrates this issue by plotting the cumulative distribution function and summary statistics of the number of days between similar rating actions on the same country. As can be seen, clustering is particularly pronounced for downgrades. In around five per cent of all cases, a downgrade on a country is followed by another downgrade on that country within just one day. For example, in the course of the Asian crisis, S\&P, Fitch and Moody's all downgraded South Korea's credit rating on successive days between 25 and 27 November 1997.

The presence of clustering might be of crucial importance when examining the spillover effects from a rating announcement since its informational content is likely to vary depending on whether it has been announced in isolation or just a few days after (or even on the same day as) a similar announcement by another agency. Not to control for these cases could 
Figure 4: Clustering of rating announcements

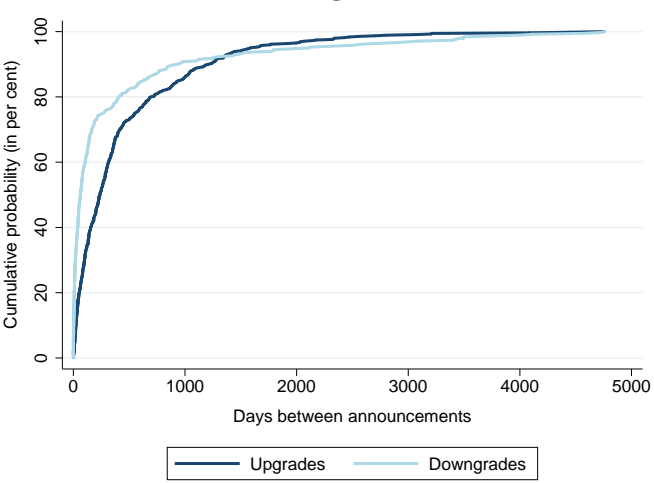

\begin{tabular}{lcc}
\hline \hline & Upgrades & Downgrades \\
\hline Mean & 453 & 364 \\
Median & 238 & 63 \\
5th pct & 13 & 1 \\
10th pct & 23 & 3 \\
25th pct & 79 & 12 \\
\hline \hline
\end{tabular}

Notes - This figure shows the cumulative distribution functions and summary statistics of the number of calendar days between an upgrade (downgrade) announcement for a given country and a subsequent upgrade (downgrade) of the same country by any agency. Information is based on the sample of 1,097 rating announcements (635 upgrades, 462 downgrades) made by S\&P, Moody's and Fitch between 1994 and 2011.

seriously bias estimation results for the impart of rating announcements on sovereign bond markets.

Clustering across countries may matter, too. When CRAs change the rating of a number of different countries in the same direction simultaneously, one needs to control for the fact that some countries will then be both "non-event" and event countries. Otherwise, one might erroneously detect spillovers across sovereign bond markets when, in fact, one is looking at a spillover in ratings. This is all the more important if the countries concerned share a common trait of some form which leads CRAs to make simultaneous announcements for the countries concerned in the first place, as appears to have happened on 3 October 2008 when Fitch downgraded Estonia, Latvia and Lithuania. It is therefore a major advantage of our dataset that it enables us to explicitly take into account prior and parallel rating actions by other CRAs and on other countries.

Similarly, the informational content of a rating change might be conditional on whether it has been preceded by the respective country being put on a watchlist. As the literature on the effects of rating announcements on the refinancing conditions of the very same country shows (eg, Afonso et al., 2012; Ismailescu and Kazemi, 2010), rating changes are often preceded by a similar change in the market's assessment of sovereign risk, especially when countries have been put "on watch", or "review", before..$^{5}$ Ignoring these anticipation

\footnotetext{
${ }^{5}$ In the following, we use the two terms interchangeably. While S\&P and Fitch issue watchlistings, in the Moody's terminology those are called "reviews".
} 
effects risks underestimating bond market reactions to a sovereign rating action. Since our dataset includes all sovereign watchlistings by the "Big Three", we can directly control for a country's watchlist status and mitigate potential problems with anticipation.

\section{$3 \quad$ Identifying sovereign spillovers}

\subsection{Counterfactual choice and estimation strategy}

The existence of rating spillover effects in the sovereign debt market requires, by definition, that the announcement by a CRA on the creditworthiness of one country (event country) impacts significantly on the bond yields of another (non-event country). Yet, the mere observation of a change in non-event country yields when an event-country announcement is made does not suffice to establish a causal relation because non-event country yields might have changed regardless. Hence, the key issue in identifying potential spillover effects is to find a suitable counterfactual.

We cannot apply the procedure traditionally used in event studies on direct announcement effects, however. This strand of literature focuses on, for instance, the bond yield response of a sovereign that has been downgraded. In this framework, effects are identified by the existence of abnormal returns, meaning that around the announcement (event window), returns are significantly different from normal, as estimated over a longer time frame before the announcement (estimation window). In order to be a reasonable guide to normal returns, the estimation window has to be chosen such that other events with a potentially significant impact on returns are excluded (see, eg, MacKinlay, 1997). In other words, the counterfactual for gauging the impact of rating announcements is "no rating change". While this represents a challenge in direct announcement studies already, which focus on countries in isolation, the identification of spillover effects based on this counterfactual is essentially impossible. 
The reason is that, in a spillover context, we would require that there be no announcements on any rated country within the estimation window. ${ }^{6}$ There is obviously a trade-off between the length of that window and the number of announcements eligible for inclusion in the estimation. However, even at a 30-day length commonly used in sovereign event studies, which is towards the shorter end of the event-study literature more generally, only 23 upgrades would be eligible, and 36 downgrades.

We therefore pursue an identification strategy that does not rely on "no rating change at all" as its counterfactual, but which discriminates between rating changes according to their severity. More precisely, rating changes of a single notch serve as the counterfactual for more severe changes of two notches or more. ${ }^{7}$ This approach is implemented in the following estimation equation, which we run on upgrades and downgrades separately:

$$
\Delta \operatorname{Spread}_{n, t}=\alpha+\beta \cdot L A R G E_{e, t}+\operatorname{RatEnv}_{e, n, t} \cdot \gamma+\operatorname{Other}_{e, n, t} \cdot \delta+\omega_{e, n, t}
$$

The dependent variable $\Delta$ Spread $_{n, t}$ is the change in non-event country $n$ 's bond spread vis-àvis the United States over the two-trading-day window $[-1,+1]$ around the announcement on day 0 of a change in the rating of event country $e(\neq n)$. The event window length accounts for the fact that by the time a CRA announces a rating change on day 0, markets in some parts of the world may have already closed. Hence, any impact on those would not materialise before day +1 , and would go undetected using a shorter $[-1,0]$ window. The same argument applies to rating announcements made after the exchange has closed in the country concerned, which we cannot distinguish from those made during trading. ${ }^{8}$

The key regressor in identifying possible spillover effects is $L A R G E_{e, t}$, a dummy that takes on a value of one if $e$ 's rating is changed by two notches or more, and zero otherwise. We thereby treat rating changes of two notches or more as one single group. This is due to the

\footnotetext{
${ }^{6}$ The universe of all rated countries is the relevant benchmark when analysing potential spillover effects in this framework. Of course, if we only required the estimation window to be free of announcements pertaining to the non-event country, the number of events eligible for inclusion would increase substantially. However, this would amount to assuming from the outset that only direct effects, as opposed to spillover effects, could possibly matter, which would defy the purpose of the investigation.

${ }^{7}$ We map CRAs' letter ratings into a linear 17-notch scale following Afonso et al. (2012).

${ }^{8}$ CRAs have made post-trading announcements during the eurozone crisis, for instance (Financial Times, 2010; Wall Street Journal, 2012). In financial markets more generally, information which is deemed highly relevant is frequently released when exchanges are closed in order to limit or smooth the impact on prices.
} 


\section{Figure 5: Distribution of rating changes}
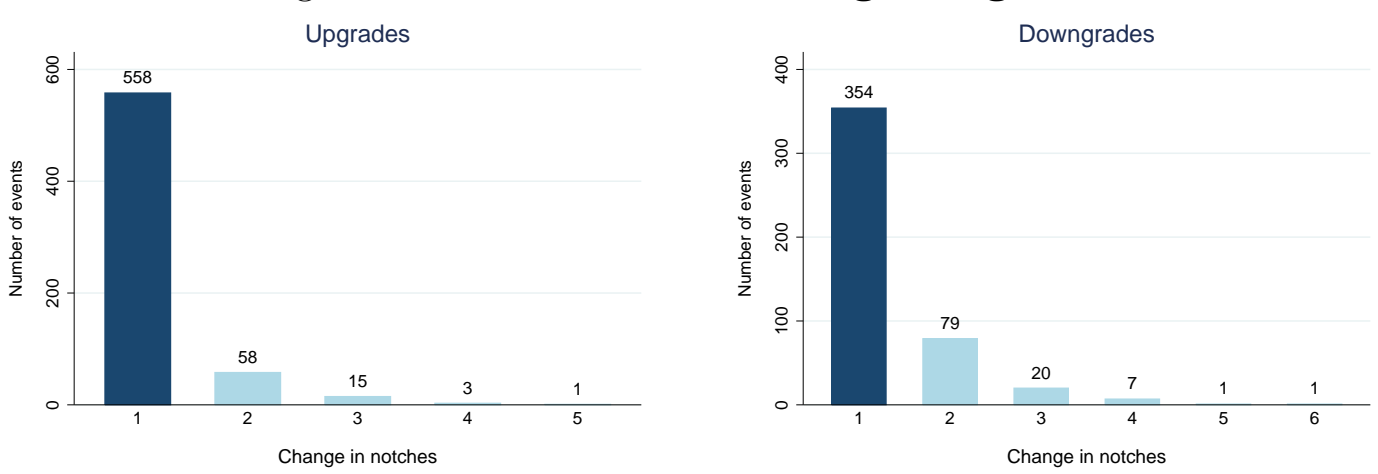

Notes - This figure shows the distribution of the severity of rating changes, measured on a 17-notch scale. Numbers are based on the sample of 1,097 rating announcements (635 upgrades, 462 downgrades) made by S\&P, Moody's and Fitch between 1994 and 2011.

distribution of the severity of upgrades and downgrades in our sample, which is shown in Figure 5 .

The vast majority of rating announcements result in a one-notch change in a country's rating. Beyond that, we observe a significant amount of events only for changes of two notches, while changes of three notches or more occur only very rarely. Therefore, we do not include separate dummy variables for the latter categories but group all rating changes of two notches or more into a single bin.

In this framework, positive (negative) spillover effects are equivalent to a drop (rise) in the spreads of country $n$ which is significantly more pronounced in response to a two-or-morenotches upgrade (downgrade) of country $e$ than to a single-notch one. We would then expect $\beta$ to be significantly negative (positive) in the upgrade (downgrade) regressions.

This counterfactual choice also has implications for the estimation technique. Since we do not use "no change" as the counterfactual (due to the estimation window problem outlined above), we identify spillover effects in pooled cross sections of upgrades and downgrades rather than in a true panel setup. ${ }^{9}$ We estimate the model by OLS.

At this point, it seems important to address some potential concerns about a possible endogeneity of the large-change dummy. The implicit assumption in the above design is that the rating announcement and its severity are not systematically related to other spread-

\footnotetext{
${ }^{9}$ Thus, $t$ denotes generic rather than actual time and can be thought of as indexing the different rating events.
} 
relevant information in the event window. Otherwise, $L A R G E$ and the error term $\omega$ would be correlated, and $\beta$ would be biased.

One concern might be, for instance, that CRAs downgrade a country instantaneously in reaction to "bad news" and do so by more notches for "particularly bad news". Note that an instantaneous response to other spread-relevant information per se would not induce any endogeneity in our framework whereas "fine-tuning" the severity of rating changes, conditional on an immediate response, clearly would. Hence, we demonstrate that there is very little to suggest instantaneous-response behaviour on the part of CRAs to begin with, and that endogeneity is therefore not a major issue in this regard. We would like to stress two points in particular.

Restricting the event window to two days already goes a long way towards alleviating the problem by limiting the amount of information that might potentially correlate with the large-change dummy. In other words, the scope for other relevant news to incite an immediate reaction from CRAs is rather small, even if such behaviour was characteristic of rating agencies and their announcements.

In addition, the proclaimed practice and a corresponding body of empirical literature suggest otherwise. The agencies state a preference for stable ratings (see, eg, Cantor, 2001; Cantor and Mann, 2003, 2007; Standard \& Poor's, 2010), intending to announce a change only if it is unlikely to be reversed in the near future. This "through the cycle" approach contrasts with a "point in time" approach in that cyclical phenomena should not, in themselves, trigger rating changes. If CRAs actually pursued a stable rating policy, the fact that cyclical and permanent factors are difficult to disentangle (International Monetary Fund, 2010) should imply some delay between new information becoming available and an ensuing change in the credit rating. Empirical evidence for corporate bond rating indicates that this practice is indeed followed, thus reducing the timeliness of rating changes (Altman and Rijken, 2004; Liu et al., 2011), and that the CRAs are "slow" in processing new information (Löffler, 2005). This perception has also been expressed in investor surveys (Association for Financial Professionals, 2002; Baker and Mansi, 2002). Moreover, Sy (2004) notes for the sovereign sector that it may simply be concerns about rating changes precipitating signifi- 
cant increases in borrowing costs or outright crises which make CRAs opt for somewhat less timely announcements.

A second concern might be biases arising from differences across agencies in a pooled setup, as pointed out by Alsakka and ap Gwilym (2012). ${ }^{10}$ Suppose, for example, that the large rating changes in our sample stemmed primarily from an agency in whose judgments the market placed more trust. Then, by pooling the announcements of S\&P, Moody's, and Fitch, we would be picking up differences in the credibility of these CRAs rather than identifying spillover effects across sovereign bond markets. However, Figure A.1 in the Appendix shows that this is not very likely, in particular for downgrades where changes of two notches or more are distributed quite evenly across agencies: 32 for S\&P, 46 for Moody's, and 30 for Fitch. ${ }^{11}$ We are therefore confident that our approach provides a sound identification of spillover effects.

\subsection{The rating environment}

The rating environment may play an important role for the bond market reaction to an upgrade or downgrade announcement. Our regressions therefore control for a number of different rating variables, contained in $\operatorname{RatEnv}_{e, n, t}$. For example, the spillover potential of a rating action might depend on the creditworthiness of the event country, which we proxy by its credit rating $\left(\right.$ InitRat $\left._{e, t}\right)$. We also include the absolute difference between the event country's initial rating and that of the non-event country $\left(\Delta\right.$ InitRat $\left._{e, n, t}\right)$ as one might expect bilateral effects to differ depending on how similar countries are in terms of creditworthiness. In addition, the impact of rating announcements may vary according to whether they have been anticipated by the market (eg, Ismailescu and Kazemi, 2010; Gande and Parsley, 2005; Reisen and von Maltzan, 1999). One potentially important and convenient measure of such anticipation is whether the actual rating action has been foreshadowed by a CRA putting the respective country on watch, or review (Afonso et al., 2012; Kaminsky and Schmukler,

\footnotetext{
${ }^{10}$ At the same time, the authors acknowledge that studies using pooled data (eg, Kaminsky and Schmukler, 2002; Sy, 2004) constitute the norm in the literature as opposed to examining rating changes by CRAs separately.

${ }^{11}$ While the picture is not quite as unambiguous for upgrades, we have already stressed in the introduction that those results should be taken with more of a grain of salt (see next section).
} 
2002). Hence, we add a dummy indicating whether a review in the indicated direction has been ongoing at the time of the upgrade or downgrade (OnWatch On,t $_{\text {) }}$.

Introducing an explicit control variable differs from Gande and Parsley (2005), who amalgamate a country's watch status into a "comprehensive credit rating". More precisely, for any given day their measure is defined as the country's actual letter rating on a 17-notch scale, raised (lowered) if the country is on review for an upgrade (downgrade). Presumably due to the counterfactual issue discussed in 3.1, Gande and Parsley (2005) then focus on those days as events on which there is a non-zero change in the comprehensive credit rating. However, this identification crucially involves additional assumptions on how changes in review status and actual rating changes relate to one another quantitatively. Furthermore, one might argue that, despite the potential anticipation effects of watchlistings, the latter are not qualitatively the same as actual rating changes. In any case, our much larger sample allows us to avoid those assumptions. We focus instead on the class of actual rating changes and their relative strengths only while controlling for anticipation through watchlistings. This should provide for a cleaner identification of spillover effects.

Moreover, we have shown in 2.2 that similar announcements by different CRAs tend to cluster around certain dates, and that this is particularly true for rating downgrades. We account for potential clustering within countries by a variable which captures the number of similar announcements made for a particular country by other agencies over a 14-day window before the respective event (SimActs $\left.W d w E v t_{e, t}\right)$. For clustering across countries, ie one or more CRAs changing the rating of more than one country in the same direction simultaneously, we include the number of similar announcements made on the same day for the "non-event" country (SimActsDayNonEvt $t_{e, t}$ ).

Finally, we add the volatility measure for the S\&P 500 Index in the United States $\left(V I X_{t}\right)$ to control for the "global market sentiment" in which the rating announcement is made. One might, for instance, imagine that in more turbulent times (ie, in which volatility is high) borrowing conditions deteriorate across the board, so that spreads over the event window would be more likely to increase in any case. In that sense, $V I X_{t}$ can be regarded as a technical control, which also adds a genuine time component to the pooled cross sections. 
All regressions include the vector Other $_{e, n, t}$ which contains a fixed set of controls, such as event and non-event country dummies. We also account for common time effects in the pooled cross sections through the inclusion of year dummies. These capture global macroeconomic trends which might be reflected in the yields of US Treasuries and, hence, spread changes. Moreover, each regression includes the following technical controls: the maturity of non-event country bonds in levels and squares to account for positions on the yield curve, a dummy for EMBI Global bond yields, and a dummy for spread changes that need to be measured over weekends as those correspond to longer intervals in terms of calendar days.

\section{Results}

\subsection{Existence of cross-border spillover effects}

Table 1 shows baseline estimation results on the existence of cross-border effects for upgrades and downgrades, respectively. We start with a parsimonious specification in Model 1, which only contains our main variable of interest, the large-change dummy $L A R G E$ and initial ratings. We then control for potential anticipation effects from watchlistings as well as clustering within and across countries in Model 2. Finally, Model 3 also accounts for global market turbulence, or risk aversion.

The key result is that the large-change dummy has the expected sign for both upgrades (ie, negative) and downgrades (ie, positive), and that it is highly significant in both cases. Moreover, this finding appears to be remarkably robust as the coefficient on $L A R G E$ is very stable and retains its significance across specifications. Comparison of the absolute coefficients, however, indicates an asymmetry in the spillover effects induced by upgrades and downgrades, respectively. Downgrades of two notches or more are associated with an average spread change over the event window which exceeds that of one-notch downgrades by about 2 basis points. In contrast, large upgrades are associated with spread changes that are roughly 1.2 basis points below those of one-notch upgrades. The asymmetry is 
Table 1: Baseline regressions

\begin{tabular}{|c|c|c|c|c|c|c|}
\hline & \multicolumn{3}{|c|}{ Panel A: Upgrades } & \multicolumn{3}{|c|}{ Panel B: Downgrades } \\
\hline & (1) & $(2)$ & $(3)$ & (1) & $(2)$ & $(3)$ \\
\hline \multirow[t]{2}{*}{$L A R G E$} & $-0.0121^{* *}$ & $-0.0124^{*}$ & $-0.0128^{*}$ & $0.0187^{* * *}$ & $0.0224^{* * *}$ & $0.0207^{* * *}$ \\
\hline & $(0.0060)$ & $(0.0064)$ & $(0.0067)$ & $(0.0061)$ & $(0.0065)$ & $(0.0066)$ \\
\hline \multirow{2}{*}{ InitRat } & 0.0001 & -0.0005 & 0.0000 & -0.0013 & -0.0013 & -0.0008 \\
\hline & $(0.0008)$ & $(0.0009)$ & $(0.0010)$ & $(0.0014)$ & $(0.0017)$ & $(0.0017)$ \\
\hline \multirow{2}{*}{$\Delta$ InitRat } & 0.0010 & 0.0008 & 0.0009 & 0.0006 & 0.0008 & 0.0008 \\
\hline & $(0.0006)$ & $(0.0006)$ & $(0.0007)$ & $(0.0008)$ & $(0.0009)$ & $(0.0009)$ \\
\hline \multirow[t]{2}{*}{ OnWatch } & & 0.0057 & 0.0070 & & $-0.0100^{*}$ & -0.0046 \\
\hline & & $(0.0055)$ & $(0.0058)$ & & $(0.0054)$ & $(0.0054)$ \\
\hline \multirow[t]{2}{*}{ SimActs WdwEvt } & & -0.0020 & -0.0013 & & $0.0170^{* * *}$ & $0.0141^{* *}$ \\
\hline & & $(0.0057)$ & $(0.0057)$ & & $(0.0064)$ & $(0.0065)$ \\
\hline \multirow[t]{2}{*}{ SimActsDayNonEvt } & & $-0.0863^{*}$ & -0.0877 & & $0.1210^{* *}$ & $0.1477^{* *}$ \\
\hline & & $(0.0512)$ & $(0.0546)$ & & $(0.0558)$ & $(0.0635)$ \\
\hline \multirow[t]{2}{*}{$V I X$} & & & $0.0017^{* * *}$ & & & $0.0006^{*}$ \\
\hline & & & $(0.0004)$ & & & $(0.0004)$ \\
\hline $\mathrm{N}$ & 31,986 & 30,564 & 29,950 & 23,734 & 22,413 & 21,931 \\
\hline Event countries & 104 & 92 & 92 & 95 & 84 & 84 \\
\hline Non-event countries & 73 & 73 & 73 & 73 & 73 & 73 \\
\hline Rating actions & 635 & 606 & 595 & 462 & 436 & 427 \\
\hline$R^{2}$ & 0.0230 & 0.0216 & 0.0223 & 0.0397 & 0.0400 & 0.0423 \\
\hline
\end{tabular}

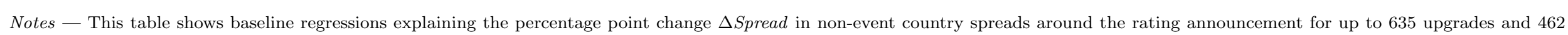

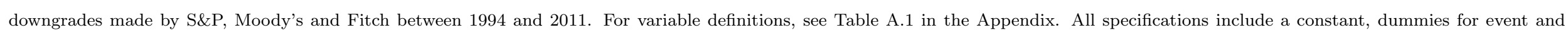

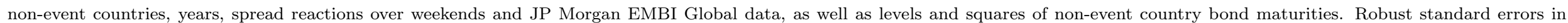
parentheses. ${ }^{* * *},{ }^{* *}$, and $*$ denote significance at the 1,5 , and 10 per cent levels, respectively. 
also reflected in the lower significance levels for upgrades despite a larger number of rating events and observations.

Asymmetries in the reactions to positive and negative events have frequently been documented in the literature. For instance, Gande and Parsley (2005) find for a 1990s sample of developed and emerging countries that negative rating events in one country affect sovereign bond spreads in others whereas there is no discernible impact for positive events. Similar results have been obtained regarding the direct effects in sovereign bond and CDS markets (Afonso et al., 2012; Larraín et al., 1997), mirroring a well-established finding from event studies on bond, stock, and CDS returns in the corporate sector (eg, Norden and Weber, 2004; Steiner and Heinke, 2001; Goh and Ederington, 1993; Hand et al., 1992). Recently, however, there has also been evidence of symmetric spillover reactions to sovereign rating announcements in the foreign exchange market (Alsakka and ap Gwilym, 2012), or even that positive announcements in emerging countries have both stronger direct and spillover effects in sovereign CDS markets (Ismailescu and Kazemi, 2010).

Turning to the rating-environment controls, neither the initial rating of the event country just before the rating announcement nor the difference in initial ratings between event and non-event country seem to play a role in terms of spillover effects. Both coefficients are far from significant across specifications. Previous evidence on this has been inconclusive. While Alsakka and ap Gwilym (2012) and Ferreira and Gama (2007) detect stronger spillover effects in the foreign exchange and stock markets, respectively, for event countries with lower initial ratings, Gande and Parsley (2005) find the opposite for bond market reactions (to sovereign downgrades).

We do find some evidence, though, that the impact of an actual rating change on spreads depends on whether it has been foreshadowed by a watchlisting. The corresponding dummy, OnWatch, is signed as expected for both upgrades and downgrades, yet there is again an asymmetry: the control variable turns out insignificant in all upgrade specifications but significant at almost the five per cent level for downgrades (Model 2 in Panel B). A possible explanation for this is given by Altman and Rijken (2006). They point out that watchlistings partially ease the tension between the market's expectation of rating stability 
and the demand for rating timeliness. This suggests that watchlistings contribute to the anticipation of actual rating changes. Given that investors tend to be more concerned about negative news, watchlistings should be more important in building anticipation for downgrades than for upgrades. Figures from our dataset support this notion. While about a third of all downgrades are preceded by a watchlisting, so are only 15 per cent of all upgrades. Finally, it has often been noted that there is an incentive to leak good news (eg, Alsakka and ap Gwilym, 2012; Christopher et al., 2012; Gande and Parsley, 2005; Goh and Ederington, 1993; Holthausen and Leftwich, 1986), so the relevance of watchlistings in building anticipation is conceivably much lower in the case of upgrades. We interpret the fact that our results are consistent with this literature as reassuring in terms of the validity of the regression specifications.

Our results also point to the importance of the clustering of rating announcements, especially for downgrades. While the controls for both clustering within (SimActsWdwEvt) and across countries (SimActsDayNonEvt) are highly significant in the downgrade regressions, the effect of across-clustering is only marginally significant once for upgrades. This appears plausible in light of the stylised facts presented in 2.2 because simultaneous announcements on several countries by one or more agencies occur much less frequently for upgrades than for downgrades. Moreover, the coefficients are correctly signed for both upgrades and downgrades, suggesting that the spread-decreasing (spread-increasing) spillover effects of an upgrade (downgrade) are all the more pronounced when one or more upgrades (downgrades) are announced for the "non-event" country at the same time.

A similar statement regarding the signs cannot be made with the same degree of confidence for SimActsWdwEvt, which measures the number of upgrades (downgrades) announced by other agencies over a 14-day window before the respective upgrade (downgrade). ${ }^{12}$ While we again find strong differences in significance between upgrades and downgrades as well

\footnotetext{
${ }^{12}$ In choosing the window length, we follow Gande and Parsley (2005) who employ a two-week duration for a comparable control variable. However, using a one-week or three-week window instead does not alter the conclusions. Moreover, the reader may note that we do not report a variable capturing similar rating announcements made on the same day by other agencies. This is due to the unattractive property that this variable drops out in the upgrade regressions since there is not a single event of multiple upgrades of a country on the same day in our sample. Therefore, in the interest of comparability, we choose not to report downgrade regressions with that control either. These regressions show, however, that the measure is always insignificant for downgrades, regardless of whether it is included in addition to, or as a stand-in for, SimActs WdwEvt. All results are available on request.
} 
as opposing signs, one need not necessarily expect within-clustering to have an additional spread-increasing effect over the event window for downgrades. Instead, the variable might subsume two opposing effects. On the one hand, the clustering of downgrades over a short interval could imply that any announcement is less relevant individually. In that case, one would expect a negative coefficient. On the other hand, clustering is much more prevalent in crisis times (see 2.2). Thus, SimActsWdwEvt tends to be higher in times of market turbulence or global risk aversion when spreads against a "safe-haven" investment like US Treasuries are upward-trending, too (eg, González-Rozada and Levy Yeyati, 2008; GarcíaHerrero and Ortíz, 2006; International Monetary Fund, 2004, 2006). As this is consistent with a positive sign, the significantly positive coefficients for downgrades suggest that we may be picking up a substantial turbulence component.

Since the literature provides little guidance on whether this is what is driving our results, we include the S\&P 500 Volatility Index (VIX), a commonly used proxy for global risk aversion (De Santis, 2012). As expected, its coefficient is positive and significant for both upgrades and downgrades, given the relation between market turbulence and yield spread drift. Interestingly, the coefficient on SimActsWdwEvt is still positive but slightly lower than before. This may be due to VIX picking up some of the turbulence effect previously captured by SimActsWdwEvt. Hence, there is indeed evidence that clustering may also reduce the spillover relevance of individual rating events that take place in a period of many similar announcements by other CRAs.

Finally, we subject our baseline regressions for downgrades to a number of robustness checks, all of which are reported in Table A.2 in the Appendix. First, we address extreme rating events. One might be concerned, for instance, that grouping all downgrades of two notches or more into a single bin could obscure the impact of a very few severe rating changes that might be driving our results (see Figure 5). However, this is not the case as dropping downgrades of four notches or more and three notches or more, respectively, leaves the findings unchanged.

Second, we ensure that the results on negative spillovers are not merely the product of specific crisis episodes, namely the eurozone crisis of 2010/11 and the Asian financial crisis 
of 1997/98. Again, our results appear to be more general as the key coefficient of interest remains robust to controlling for these two crises.

Third, in 3.1 we have already argued that an estimation bias due to different degrees of trust being placed in the three CRAs is unlikely by pointing to the distribution of the severity of rating changes across agencies in Figure A.1 (see the Appendix). However, the figure also shows that $\mathrm{S} \& \mathrm{P}$ stands out as the agency which is far less likely than the other two CRAs to issue a large downgrade conditional on announcing any downgrade at all (only 32 out of 210 negative announcements). By virtue of their relative rarity, S\&P's large downgrades might hint at particularly strong deteriorations in a country's creditworthiness and thus incite especially strong reactions as well. One might therefore be concerned that those might account for our baseline result. ${ }^{13}$ Yet, controlling for this does nothing to alter the conclusion of significant cross-border spillover effects of sovereign rating downgrades in general.

\subsection{Spillover channels}

After providing evidence for the existence of spillover effects in the sovereign bond market, in particular for downgrades, we now turn to potential channels of those spillovers. While the regressions presented so far control for a multiplicity of factors pertaining to event and nonevent countries on their own, they do not - with the exception of $\Delta$ InitRat - account for bilateral characteristics of event and non-event countries. However, bond market reactions in the wake of rating announcements in other countries might differ depending on similarities and bilateral linkages, which may be highly relevant from the perspective of policymakers.

We therefore augment our final baseline specification (Model 3 in Table 1) by whether the event and non-event country belong to the same geographical region (Region), whether they are members of a common major trade bloc (TradeBloc), and the importance of the event

\footnotetext{
${ }^{13}$ Moreover, some studies, such as Ismailescu and Kazemi (2010), continue to single out S\&P and ignore other CRAs' announcements on the grounds that early research into sovereign credit rating announcements found S\&P's to be less anticipated (eg, Gande and Parsley, 2005; Reisen and von Maltzan, 1999). It is worth emphasising, though, that an agency such as Fitch, for example, only entered the business as late as 1994. Therefore, not only were there no corresponding rating actions to examine by earlier studies to begin with but it is also quite conceivable that part of S\&P's alleged special position was eroded over time. The summary of more recent research provided in Alsakka and ap Gwilym (2012) also suggests that there is no single agency whose announcements are generally more relevant than those of the other two CRAs.
} 
country as an export destination for the non-event country (ExpImpEvt). We also account for the degree of financial integration by the event and non-event country's capital account openness (CapOpenEvt and CapOpenNonEvt). Finally, we consider the size of the event country's GDP (SizeEvt) as well as differences between event and non-event countries in terms of GDP $(\Delta$ Size $)$ and trend growth $(\Delta$ TrendGrowth). Definitions and sources for all control variables are reported in Table A.1 in the Appendix. The results are shown in Tables 2 and 3.

There is again a notable asymmetry between the findings on upgrades and those on downgrades. This applies to both the results on the potential channels themselves and to the impact that the inclusion of additional controls has on the robustness of our baseline findings. Whereas the results for downgrades are highly stable and intuitive, they paint a more nuanced picture for upgrades.

In more detail, we find consistently that spillover effects are significantly stronger within the same region in the case of downgrade announcements. The coefficient on Region has the correct sign, indicating that borrowing costs increase by up to almost four basis points more for non-event countries in the same region as the event country than for those outside it. Our findings appear plausible since countries in the same geographical region are more likely to share institutional or cultural characteristics and to have important real and financial links to one another. Apart from fundamental factors, a more mundane explanation might posit that financial markets simply find non-event countries from the same region "guilty by association". The results are also in line with a number of studies which focus on one or more particular regions from the start (eg, Alsakka and ap Gwilym, 2012; Arezki et al., 2011; De Santis, 2012). Surprisingly, we obtain positive coefficients for upgrades as well, which would suggest that those are less likely to induce spillovers within than across regions. While one could imagine that belonging to a particular region does not matter for upgrade announcements due to an asymmetric perception by investors, the fact that the coefficients are often significant is not easily rationalised. On a positive note, though, the magnitude for upgrades is only about a third of that for downgrades. Therefore, in the interest of comparability and as an important economic control, we retain Region in all specifications. 
Table 2: Spillover channels, upgrades

\begin{tabular}{lccccccc}
\hline \hline \multirow{2}{*}{ LARGE } & $(1)$ & $(2)$ & $(3)$ & $(4)$ & $(5)$ & $(6)$ & $(7)$ \\
InitRat & $-0.0128^{*}$ & $-0.0128^{*}$ & -0.0111 & -0.0094 & $-0.0117^{*}$ & $-0.0142^{* *}$ & $-0.0115^{*}$ \\
& $(0.0067)$ & $(0.0067)$ & $(0.0071)$ & $(0.0071)$ & $(0.0068)$ & $(0.0066)$ & $(0.0069$ \\
SInitRat & 0.0000 & 0.0001 & -0.0005 & 0.0012 & $0.0027^{* *}$ & $0.0031^{* * *}$ & $0.0032^{* *}$ \\
& $(0.0010)$ & $(0.0010)$ & $(0.0010)$ & $(0.0012)$ & $(0.0013)$ & $(0.0012)$ & $(0.0014)$ \\
OnWatch & 0.0009 & 0.0010 & 0.0006 & 0.0006 & $0.0012^{*}$ & 0.0011 & 0.0008 \\
& $(0.0007)$ & $(0.0007)$ & $(0.0007)$ & $(0.0008)$ & $(0.0007)$ & $(0.0007)$ & $(0.0008)$ \\
SimActsWdwEvt & 0.0070 & 0.0070 & 0.0066 & 0.0065 & 0.0080 & 0.0085 & 0.0072 \\
\multirow{4}{*}{ SimActsDayNonEvt } & $(0.0058)$ & $(0.0058)$ & $(0.0060)$ & $(0.0061)$ & $(0.0059)$ & $(0.0061)$ & $(0.0063)$ \\
& -0.0013 & -0.0013 & -0.0058 & -0.0071 & -0.0026 & -0.0032 & -0.0090 \\
VIX & $(0.0057)$ & $(0.0057)$ & $(0.0059)$ & $(0.0060)$ & $(0.0058)$ & $(0.0059)$ & $(0.0062)$ \\
& -0.0877 & -0.0903 & -0.1024 & $-0.1059^{*}$ & -0.0883 & -0.0950 & $-0.1128^{*}$ \\
Region & $(0.0546)$ & $(0.0549)$ & $(0.0625)$ & $(0.0642)$ & $(0.0546)$ & $(0.0578)$ & $(0.0681)$ \\
& $0.0017^{* * *}$ & $0.0017^{* * *}$ & $0.0019^{* * *}$ & $0.0018^{* * *}$ & $0.0017^{* * *}$ & $0.0018^{* * *}$ & $0.0019^{* * *}$ \\
TradeBloc & $(0.0004)$ & $(0.0004)$ & $(0.0004)$ & $(0.0004)$ & $(0.0004)$ & $(0.0004)$ & $(0.0004)$ \\
& & 0.0109 & $0.0146^{*}$ & $0.0144^{*}$ & $0.0128^{*}$ & $0.0125^{*}$ & $0.0169^{* *}$ \\
ExpImpEvt & $(0.0071)$ & $(0.0080)$ & $(0.0081)$ & $(0.0073)$ & $(0.0075)$ & $(0.0084)$ \\
& & & -0.0100 & -0.0093 & & & $-0.0125^{*}$ \\
& & & $(0.0065)$ & $(0.0065)$ & & & $(0.0069)$ \\
& & & -0.1080 & -0.1112 & & & -0.0916 \\
& & & & & & & $(0.2148)$
\end{tabular}

(continued on next page) 


\section{Spillover channels, upgrades (continued)}

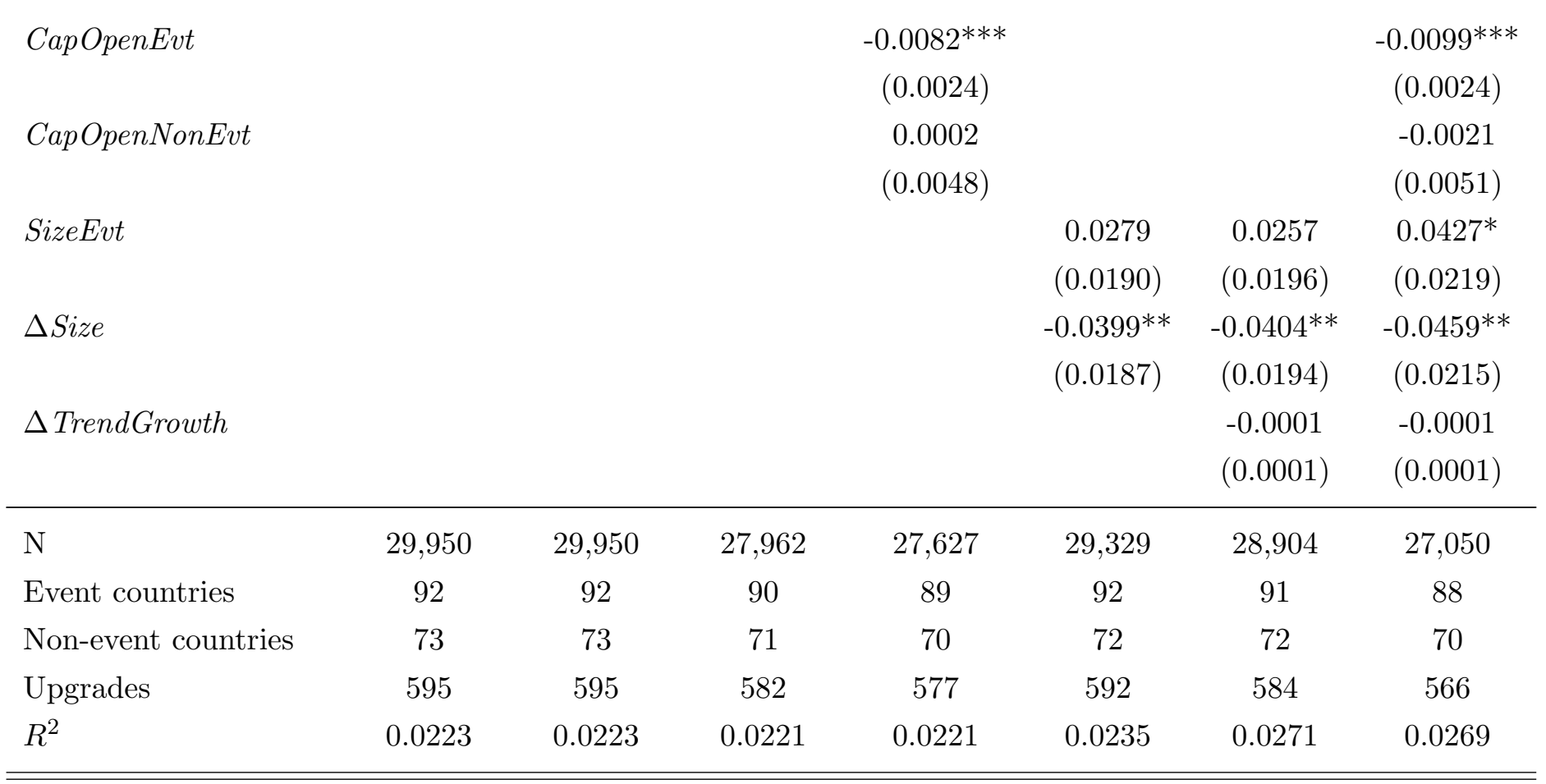

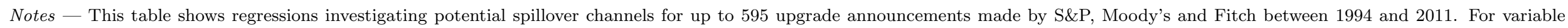

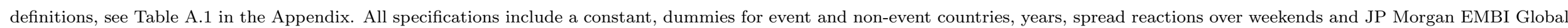
data, as well as levels and squares of non-event country bond maturities. Robust standard errors in parentheses. $* * *, * *$, and $*$ denote significance at the 1,5 , and 10 per cent levels, respectively. 
Table 3: Spillover channels, downgrades

\begin{tabular}{|c|c|c|c|c|c|c|c|}
\hline & (1) & $(2)$ & (3) & (4) & (5) & (6) & (7) \\
\hline$L A R G E$ & $\begin{array}{c}0.0207^{* * *} \\
(0.0066)\end{array}$ & $\begin{array}{c}0.0206^{* * *} \\
(0.0066)\end{array}$ & $\begin{array}{c}0.0217^{* * *} \\
(0.0069)\end{array}$ & $\begin{array}{c}0.0231^{* * *} \\
(0.0069)\end{array}$ & $\begin{array}{c}0.0222^{* * *} \\
(0.0070)\end{array}$ & $\begin{array}{c}0.0224^{* * *} \\
(0.0070)\end{array}$ & $\begin{array}{c}0.0244^{* * *} \\
(0.0073)\end{array}$ \\
\hline InitRat & $\begin{array}{l}-0.0008 \\
(0.0017)\end{array}$ & $\begin{array}{l}-0.0006 \\
(0.0017)\end{array}$ & $\begin{array}{l}-0.0010 \\
(0.0018)\end{array}$ & $\begin{array}{l}-0.0014 \\
(0.0018)\end{array}$ & $\begin{array}{l}-0.0017 \\
(0.0019)\end{array}$ & $\begin{array}{l}-0.0017 \\
(0.0019)\end{array}$ & $\begin{array}{l}-0.0031 \\
(0.0021)\end{array}$ \\
\hline$\Delta$ InitRat & $\begin{array}{c}0.0008 \\
(0.0009)\end{array}$ & $\begin{array}{c}0.0012 \\
(0.0009)\end{array}$ & $\begin{array}{l}0.0017^{*} \\
(0.0010)\end{array}$ & $\begin{array}{c}0.0015 \\
(0.0011)\end{array}$ & $\begin{array}{c}0.0008 \\
(0.0010)\end{array}$ & $\begin{array}{c}0.0008 \\
(0.0010)\end{array}$ & $\begin{array}{c}0.0013 \\
(0.0011)\end{array}$ \\
\hline OnWatch & $\begin{array}{l}-0.0046 \\
(0.0054)\end{array}$ & $\begin{array}{l}-0.0046 \\
(0.0054)\end{array}$ & $\begin{array}{l}-0.0031 \\
(0.0058)\end{array}$ & $\begin{array}{l}-0.0042 \\
(0.0058)\end{array}$ & $\begin{array}{l}-0.0009 \\
(0.0056)\end{array}$ & $\begin{array}{l}-0.0008 \\
(0.0057)\end{array}$ & $\begin{array}{l}-0.0003 \\
(0.0059)\end{array}$ \\
\hline SimActsWdwEvt & $\begin{array}{c}0.0141^{* *} \\
(0.0065)\end{array}$ & $\begin{array}{c}0.0141^{* *} \\
(0.0065)\end{array}$ & $\begin{array}{c}0.0135^{* *} \\
(0.0066)\end{array}$ & $\begin{array}{c}0.0137^{* *} \\
(0.0067)\end{array}$ & $\begin{array}{c}0.0146^{* *} \\
(0.0067)\end{array}$ & $\begin{array}{c}0.0146^{* *} \\
(0.0067)\end{array}$ & $\begin{array}{c}0.0141^{* *} \\
(0.0069)\end{array}$ \\
\hline SimActsDayNonEvt & $\begin{array}{c}0.1477^{* *} \\
(0.0648)\end{array}$ & $\begin{array}{c}0.1451^{* *} \\
(0.0643)\end{array}$ & $\begin{array}{c}0.1426^{* *} \\
(0.0653)\end{array}$ & $\begin{array}{c}0.1170^{*} \\
(0.0610)\end{array}$ & $\begin{array}{c}0.1160^{*} \\
(0.0623)\end{array}$ & $\begin{array}{c}0.1161^{*} \\
(0.0623)\end{array}$ & $\begin{array}{l}0.1136^{*} \\
(0.0619)\end{array}$ \\
\hline$V I X$ & $\begin{array}{l}0.0006^{*} \\
(0.0004)\end{array}$ & $\begin{array}{l}0.0006^{*} \\
(0.0004)\end{array}$ & $\begin{array}{c}0.0006 \\
(0.0004)\end{array}$ & $\begin{array}{c}0.0006 \\
(0.0004)\end{array}$ & $\begin{array}{l}0.0006^{*} \\
(0.0004)\end{array}$ & $\begin{array}{l}0.0006^{*} \\
(0.0004)\end{array}$ & $\begin{array}{c}0.0005 \\
(0.0004)\end{array}$ \\
\hline Region & & $\begin{array}{c}0.0376^{* *} \\
(0.0153)\end{array}$ & $\begin{array}{c}0.0329 * * \\
(0.0164)\end{array}$ & $\begin{array}{c}0.0350 * * \\
(0.0166)\end{array}$ & $\begin{array}{c}0.0379 * * \\
(0.0157)\end{array}$ & $\begin{array}{c}0.0380^{* *} \\
(0.0157)\end{array}$ & $\begin{array}{c}0.0348^{* *} \\
(0.0168)\end{array}$ \\
\hline TradeBloc & & & $\begin{array}{c}0.0159 \\
(0.0111)\end{array}$ & $\begin{array}{c}0.0120 \\
(0.0116)\end{array}$ & & & $\begin{array}{c}0.0120 \\
(0.0121)\end{array}$ \\
\hline ExpImpEvt & & & $\begin{array}{c}0.0687 \\
(0.2200)\end{array}$ & $\begin{array}{c}0.0746 \\
(0.2237)\end{array}$ & & & $\begin{array}{c}0.0580 \\
(0.2268)\end{array}$ \\
\hline
\end{tabular}

(continued on next page) 


\section{Spillover channels, downgrades (continued)}

\begin{tabular}{|c|c|c|c|c|c|c|c|}
\hline CapOpenEvt & & & & $\begin{array}{l}0.0102^{*} \\
(0.0060)\end{array}$ & & & $\begin{array}{c}0.0126^{* *} \\
(0.0063)\end{array}$ \\
\hline \multirow[t]{2}{*}{ CapOpenNonEvt } & & & & 0.0090 & & & 0.0081 \\
\hline & & & & $(0.0083)$ & & & $(0.0088)$ \\
\hline \multirow[t]{2}{*}{ SizeEvt } & & & & & 0.0222 & 0.0221 & 0.0247 \\
\hline & & & & & $(0.0290)$ & $(0.0294)$ & $(0.0330)$ \\
\hline \multirow[t]{2}{*}{$\Delta$ Size } & & & & & -0.0169 & -0.0170 & -0.0146 \\
\hline & & & & & $(0.0218)$ & $(0.0223)$ & $(0.0253)$ \\
\hline$\Delta$ TrendGrowth & & & & & & 0.0000 & 0.0000 \\
\hline $\mathrm{N}$ & 21,931 & 21,931 & 20,633 & 20,352 & 21,031 & 20,885 & 19,724 \\
\hline Event countries & 84 & 84 & 81 & 80 & 82 & 82 & 79 \\
\hline Non-event countries & 73 & 73 & 71 & 70 & 72 & 72 & 70 \\
\hline Downgrades & 427 & 427 & 416 & 414 & 416 & 416 & 405 \\
\hline$R^{2}$ & 0.0423 & 0.0428 & 0.0423 & 0.0416 & 0.0441 & 0.0442 & 0.0434 \\
\hline
\end{tabular}

Notes — This table shows regressions investigating potential spillover channels for up to 427 downgrade announcements made by S\&P, Moody's and Fitch between 1994 and 2011 . For variable

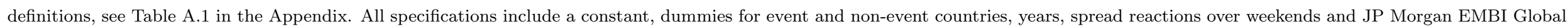
data, as well as levels and squares of non-event country bond maturities. Robust standard errors in parentheses. $* * *, * *$, and $*$ denote significance at the 1,5 , and 10 per cent levels, respectively. 
The two trade controls, ie common membership in a major trade bloc (TradeBloc) and the non-event country's ratio of exports to the event country to domestic GDP (ExpImpEvt), are signed as expected throughout, pointing to more pronounced spillover effects for both upgrades and downgrades when such linkages exist, or when they are stronger. However, they are only mildly significant once for upgrades (see Model 7 in Table 2). Moreover, the stability in magnitude and significance of Region upon inclusion of the trade variables, in particular for downgrades, seems to indicate that stronger spillover effects within regions cannot easily be explained by real linkages. ${ }^{14}$

Besides real linkages, we would ideally also like to control directly for bilateral financial linkages, eg the exposure of non-event country investors to event country sovereign bonds. Unfortunately, even use of the most comprehensive data from the IMF's Coordinated Portfolio Investment Survey leads to a massive reduction in the number of observations and major selection effects along the time series and country dimensions, which renders virtually impossible any comparison with the baseline results.

However, to the extent that trade also captures a notable portion of variation in bilateral asset holdings, our findings for real linkages also hold for financial linkages. As shown by Aviat and Coeurdacier (2007), there is indeed strong evidence that trade is a powerful determinant of bilateral (bank) asset holdings. ${ }^{15}$ The disadvantage of using trade as a proxy for financial linkages is, however, that we cannot discriminate between the effects of real and financial linkages.

To get an idea of the distinct impact of financial linkages, we therefore approximate financial integration by the degree of the event and non-event country's capital account openness as measured by the Chinn-Ito index (Chinn and Ito, 2006). ${ }^{16}$ While this index cannot be used to gauge the effects of bilateral financial linkages, it is still interesting in its own right to look at and control for the level effects. The results show that the event country's capital

\footnotetext{
${ }^{14}$ The fact that the correlation of the two trade variables with the region control is low does not support multicollinearity as a technical explanation for this result. Moreover, replacing ExpImpEvt by other proxies for bilateral trade does not change the picture either. These results are available upon request.

${ }^{15}$ In addition, through its correlation with FDI, trade may proxy for cross-country bank exposure since bank lending may follow domestic companies when those set up operations abroad (eg, Goldberg and Saunders, 1980, 1981; Brealey and Kaplanis, 1996; Yamori, 1998).

${ }^{16}$ We choose this index due to its broad coverage over time, which allows us to maintain comparability with the baseline results. The index has also been used extensively in recent literature (eg, Frankel et al., 2013; Fratzscher, 2012; Hale and Spiegel, 2012).
} 
account openness tends to significantly amplify cross-border spillover effects. Since bonds of financially open countries should be more likely to be held by foreign investors, this result is highly intuitive.

The evidence on the remaining potential channels is succinctly summarised for downgrades. In no specification do the size of the event country's GDP (SizeEvt), its increment over that of the non-event country $(\Delta$ Size $)$, or differences in trend growth between event and non-event countries ( $\Delta$ TrendGrowth) turn out to be significant determinants of the strength of bond market spillovers. At the same time, all results from the baseline and augmented baseline regressions (Models 1 and 2 in Table 3) prove remarkably stable in terms of both magnitude and significance.

This contrasts with the corresponding findings for upgrades. On the one hand, we obtain a number of interesting results for the size and growth controls. On the other hand, the augmented regressions raise some doubts on our main variable of interest, $L A R G E$, in terms of statistical significance. The latter alternates between specifications and vanishes in some, yet in view of the considerably stronger baseline results for downgrades, this is not entirely surprising. It merely serves to underscore the asymmetry that exists between positive and negative rating changes. However, this also means that the evidence on the potential channels for upgrades should be taken with a grain of salt.

In this regard, the most interesting result is probably the observation that, given the event country's size and initial rating, positive spillovers are larger the smaller the non-event country relative to the event country $(\Delta$ Size $)$. The magnitude of the coefficient suggests that non-event countries which are half (two-thirds) the size of the event country experience an additional positive spillover effect of about four (two) basis points, as compared to nonevent countries as large as the event country. ${ }^{17}$ While the effect appears to be relatively small, its direction is still interesting, in particular when viewed in conjunction with the fact that, across the whole sample, larger and more highly rated countries induce smaller spillovers (Models 5 to 7 in Table 2). This would be consistent with a world in which

\footnotetext{
${ }^{17} \Delta$ Size is defined as the difference between the event and non-event country's log GDPs or, equivalently, the $\log$ of the ratio of the two GDP levels. Therefore, a decrease in relative non-event country size by half (two-thirds) amounts to an increase in $\Delta$ Size of about one hundred (fifty) per cent. With an absolute coefficient of roughly 0.04 , the (semi-elasticity) marginal effects therefore obtain as four and two basis points, respectively.
} 
positive spillover effects matter primarily within a group of small developed and emerging countries but less so within a group of large, developed countries, and in which the latter have little impact on the former. The insignificance of the absolute difference in trend GDP growth rates between event and non-event countries ( $\Delta$ TrendGrowth) as a further measure of differences in economic development does nothing to contradict this interpretation. In view of the generally more ambiguous results for upgrades, however, we do not wish to overemphasise this point.

\subsection{Discussion}

Our results can be condensed into the following stylised facts. First, there is strong evidence of statistically significant, negative spillover effects of downgrade announcements. This result proves highly robust to controlling for anticipation through watchlistings and the clustering of rating announcements. Second, negative spillover effects are more pronounced among countries in a common region, which cannot be explained by measurable fundamental links and similarities between countries. Third, reactions to upgrades are, if anything, much more muted than for downgrades, suggesting important asymmetries in the sovereign bond market's treatment of the two types of announcements. Fourth, evidence on the channels behind positive spillover effects, if any, offers a more complex picture and appears relatively ambiguous.

So, which conclusion to draw from this? To begin with, there is a strong case for the notion that negative sovereign rating announcements, ie those of most concern to policymakers, do matter in inducing spillovers across markets. Such is the outcome of the explicit identification strategy used in this paper, which demonstrates that, all other things equal, "large" downgrades of two notches or more cause larger hikes in spreads than "small" one-notch downgrades. This suggests a role for CRAs and their actions in sovereign bond markets, be it through the revelation of new information on creditworthiness which acts as a "wake-up call" for investors to reassess fundamentals in other countries (Goldstein, 1998), or simply by providing a coordinating signal that shifts expectations from a good to a bad equilibrium (Boot et al., 2006; Masson, 1998). 
However, a major regulatory focus on the activities of CRAs would also require negative spillover effects of substantial economic magnitude. In this paper, we find the incremental impact of "large" downgrades to be a little over two basis points, which may appear limited at first glance. Yet, it is important to note that this does not represent the total effect that policymakers would be concerned about. This can be thought of as consisting of a "base effect" that "small" downgrades have, compared to a benchmark scenario of no downgrades anywhere, plus an additional impact for "large" downgrades - which is what we measure. Of course, the reason we focus on the latter lies in the impossibility of cleanly identifying the "base effects" of rating changes unless one rules out the existence of rating-induced spillovers from the beginning (see the discussion in 3.1). Nonetheless, the total effect is conceivably a multiple of the one we estimate. At factors of 2 and 5, for instance, the implied total effects amount to approximately 4 and 10 basis points, respectively. To put this into perspective, the average sovereign bond spread vis-à-vis US Treasuries at the time of the downgrade announcements in our sample is 3.25 per cent, or 325 basis points. While the total effect of downgrades is relatively small in comparison, one has to bear in mind that governments often need to refinance large amounts of debt, which magnifies the impact of even small spread differences. Moreover, there is still a regional effect of up to 4 basis points on top of that, suggesting that concerns about negative spillovers in the sovereign debt market should not be lightly dismissed.

Finally, from a policymaker's point of view, the finding that the increased strength of negative spillovers within regions cannot be explained away by measurable linkages and similarities between countries might also be a cause for concern. Even though limited data availability precludes an all-encompassing analysis of potential channels, there is little to suggest that one can comfortably rule out that some countries are found "guilty by association" with the event country. Moreover, such behaviour on the part of investors would likely extend to their reactions to news other than rating announcements. While it is hard to see an obvious remedy, the potential problem would seem to be much more general and, above all, rooted in investor behaviour. Hence, it is not clear that putting the primary emphasis on CRAs will prove effective in this regard. 


\section{Conclusion}

Concerns about negative spillovers across sovereign debt markets in the wake of sovereign rating changes have recently resurfaced on the agenda of policymakers. In this paper, we study the existence and potential channels of such spillover effects. More specifically, we avail of an extensive dataset which covers all sovereign rating announcements made by the three major agencies and daily sovereign bond market movements of up to 73 developed and emerging countries between 1994 and 2011. Based on this, we propose an explicit counterfactual identification strategy which compares the bond market reactions to small changes in an agency's assessment of a country's creditworthiness to those induced by all other, more major revisions. In doing so, we account for a number of factors that might impact on the reception of individual announcements.

We find strong evidence in favour of negative cross-border spillovers in the wake of sovereign downgrades. At the same time, there is no similarly robust indication as to positive spillovers since reactions to upgrades are much more muted at best, which points to an important asymmetry in the sovereign debt market's treatment of positive and negative information. Regarding the channels of negative spillover effects, our results suggest that those are more pronounced for countries within the same region. Strikingly, however, this cannot be explained by fundamental linkages and similarities, such as trade, which turn out to be insignificant.

Therefore, there is reason to believe that policymakers' concerns about negative spillover effects are not unfounded. In fact, the lack of power of a set of fundamentals in explaining the added regional component may reinforce, or give rise to, concerns about the ability of investors to discriminate accurately between sovereigns. This could also be of more general interest because such behaviour is likely to carry over to reactions to various kinds of nonCRA news in other markets and sectors, too. Hence, important though they are, a sole focus on CRAs and their actions might be missing a bigger picture. 


\section{References}

Afonso, A., D. Furceri, And P. Gomes (2012): "Sovereign credit ratings and financial markets linkages: Application to European data," Journal of International Money and Finance, 31, 606-638.

AlsakKa, R. And O. AP Gwilym (2012): "Foreign exchange market reactions to sovereign credit news," Journal of International Money and Finance, 31, 845-864.

Altman, E. I. And H. A. RiJken (2004): "How Rating Agencies Achieve Rating Stability," Journal of Banking \& Finance, 28, 2679-2714.

(2006): "The Added Value of Rating Outlooks and Rating Reviews to Corporate Bond Ratings," Working Paper, NYU Salomon Center.

Arezki, R., B. Candelon, And A. N. R. Sy (2011): "Sovereign Rating News and Financial Markets Spillovers: Evidence from the European Debt Crisis," IMF Working Paper Series 11/68.

Association for Financial Professionals (2002): "Rating Agencies Survey: Accuracy, Timeliness, and Regulation," November.

Aviat, A. And N. Coeurdacier (2007): "The geography of trade in goods and asset holdings," Journal of International Economics, 71, 22-51.

Baker, H. K. And S. A. MAnsi (2002): "Assessing Credit Rating Agencies," Journal of Business Finance \&f Accounting, 29, 1367-1398.

Boot, A. W. A., T. A. Milbourn, And A. Schmeits (2006): "Credit Ratings as Coordination Mechanisms," Review of Financial Studies, 19, 81-118.

Brealey, R. A. And E. C. Kaplanis (1996): "The determination of foreign banking location," Journal of International Money and Finance, 15, 577-597.

Brooks, R., R. W. FAfF, D. Hillier, And J. Hillier (2004): "The national market impact of sovereign rating changes," Journal of Banking \& Finance, 28, 233-250.

CAntor, R. (2001): "Moody's investors service response to the consultative paper issued by the Basel Committee on Bank Supervision "A new capital adequacy framework"," Journal of Banking \& Finance, 25, 171-185.

Cantor, R. And C. Mann (2003): "Measuring the Performance of Corporate Bond Ratings," Special comment, Moody's Investors Service, New York.

(2007): "Analyzing the Tradeoff between Ratings Accuracy and Stability," Journal of Fixed Income, 16, 60-68. 
Cantor, R. And F. PACKer (1996): "Determinants and impact of sovereign credit ratings," Economic Policy Review, 37-53.

Chinn, M. D. And H. Ito (2006): "What matters for financial development? Capital controls, institutions, and interactions," Journal of Development Economics, 81, 163-192.

Christopher, R., S.-J. Kim, And E. Wu (2012): "Do sovereign credit ratings influence regional stock and bond market interdependencies in emerging countries?" Journal of International Financial Markets, Institutions and Money, 22, 1070-1089.

DE SAntis, R. A. (2012): "The euro area sovereign debt crisis: safe haven, credit rating agencies and the spread of the fever from Greece, Ireland and Portugal," Working Paper No. 1419, European Central Bank.

European Union (2013): "Regulation (EU) No 462/2013 of the European Parliament and of the Council of 21 May 2013 amending Regulation (EC) No 1060/2009 on credit rating agencies Text with EEA relevance," Official Journal of the European Union, 56, 1-33.

Ferreira, M. A. And P. M. Gama (2007): "Does sovereign debt ratings news spill over to international stock markets?" Journal of Banking \& Finance, 31, 3162-3182.

Financial Times (2010): "German MPs claim Greece needs $€ 120$ bn," 28 April 2010. (2011): "Rating agencies face shake-up," 21 October 2011.

Frankel, J. A., C. A. Vegh, And G. Vuletin (2013): "On graduation from fiscal procyclicality," Journal of Development Economics, 100, 32-47.

Fratzscher, M. (2012): "Capital flows, push versus pull factors and the global financial crisis," Journal of International Financial Economics, 88, 341-356.

Gande, A. And D. C. PARsley (2005): "News spillovers in the sovereign debt market," Journal of Financial Economics, 75, 691-734.

García-Herrero, A. And A. Ortíz (2006): "The Role of Global Risk Aversion in Explaining Sovereign Spreads," Economía, 7, 125-155.

Goh, J. C. And L. H. Ederington (1993): "Is a Bond Rating Downgrade Bad News, Good News, or No News for Stockholders?" Journal of Finance, 48, 2001-2008.

GoldberG, L. G. And A. Saunders (1980): "The Causes of U.S. Bank Expansion Overseas: The Case of Great Britain," Journal of Money, Credit and Banking, 12, 630643.

(1981): "The determinants of foreign banking activity in the United States," Journal of Banking \& Finance, 5, 17-32. 
Goldstein, M. (1998): The Asian Crisis: Causes, Cures, and Systemic Implications, Washington, D.C.: Institute for International Economics.

GonzÁlez-Rozada, M. And E. Levy Yeyati (2008): "Global Factors and Emerging Market Spreads," The Economic Journal, 118, 1917-1936.

Hale, G. B. And M. M. Spiegel (2012): "Currency composition of international bonds: The EMU effect," Journal of International Economics, 88, 134-149.

Hand, J. R. M., R. W. Holthausen, and R. W. Leftwich (1992): "The Effect of Bond Rating Agency Announcements on Bond and Stock Prices," Journal of Finance, 47, 733-752.

Hill, P. AND R. FAfF (2010): "The Market Impact of Relative Agency Activity in the Sovereign Ratings Market," Journal of Business Finance $\&$ Accounting, 37, 1309-1347.

Holthausen, R. W. And R. W. Leftwich (1986): "The Effect of Bond Rating Changes on Common Stock Prices," Journal of Financial Economics, 62, 57-89.

Hooper, V., T. Hume, And S.-J. Kim (2008): "Sovereign rating changes-Do they provide new information for stock markets?" Economic Systems, 32, 142-166.

International Monetary Fund (2004): Global Financial Stability Report, September 2004, chap. Global Financial Market Developments, 8-80.

(2006): Global Financial Stability Report, September 2006, chap. Assessing Global Financial Risks, 1-45.

(2010): Global Financial Stability Report, October 2010, chap. The Uses and Abuses of Sovereign Credit Ratings, 85-122.

ISMAILESCU, I. AND H. KAZEMI (2010): "The reaction of emerging market credit default swap spreads to sovereign credit rating changes," Journal of Banking Es Finance, 34, 2861-2873.

JP Morgan (1999): "Introducing the J.P. Morgan Emerging Markets Bond Index Global (EMBI Global)," August.

Kaminsky, G. And S. L. Schmukler (2002): "Emerging Markets Instability: Do Sovereign Ratings Affect Country Risk and Stock Returns?" World Bank Economic Review, 16, 171-195.

Kaminsky, G. L. And S. L. Schmukler (1999): "What Triggers Market Jitters? - A Chronicle of the Asian Crisis," Journal of International Money and Finance, 18, 537-60. 
Larraín, G., H. Reisen, And J. von Maltzan (1997): "Emerging Market Risk and Sovereign Credit Ratings," OECD Development Centre Working Papers 124, OECD Publishing.

Liu, P., J. S. Jones, And J. Y. Gu (2011): "Do Credit Rating Agencies Sacrifice Timeliness by Pursuing Rating Stability? Evidence from Equity Market Reactions to CreditWatch Events," Paper presented at the 2011 EFMA Annual Meeting, Braga (Portugal).

LÖffler, G. (2005): "Avoiding the Rating Bounce: Why Rating Agencies are Slow to React to New Information," Journal of Economic Behavior and Organization, 56, 365381.

MacKinlay, A. C. (1997): "Event Studies in Economics and Finance," Journal of Economic Literature, 35, 13-39.

Masson, P. (1998): "Contagion: Monsoonal Effects, Spillovers, and Jumps Between Multiple Equilibria," IMF Working Paper Series 98/142.

Norden, L. And M. Weber (2004): "Informational Efficiency of Credit Default Swap and Stock Markets: The Impact of Credit Rating Announcements," Journal of Banking E Finance, 28, 2813-2843.

Reisen, H. And J. von Maltzan (1999): "Boom and Bust in Sovereign Ratings," International Finance, 2, 273-293.

StAndARD \& Poor's (2010): "Methodology: Credit Stability Criteria," Standard \& Poor's RatingsDirect.

Steiner, M. And V. G. Heinke (2001): "Event Study Concerning International Bond Price Effects of Credit Rating Actions," International Journal of Finance and Economics, $6,139-157$.

Sy, A. (2004): "Rating the rating agencies: Anticipating currency crises or debt crises?" Journal of Banking \& Finance, 28, 2845-2867.

Wall Street Journal (2012): "Moody's Poised to Decide on Spain," 28 September 2012.

YAMORI, N. (1998): "A note on the location choice of multinational banks: The case of Japanese financial institutions," Journal of Banking \& Finance, 22, 109-120. 


\section{Appendix}

Figure A.1: Distribution of rating changes, by agency
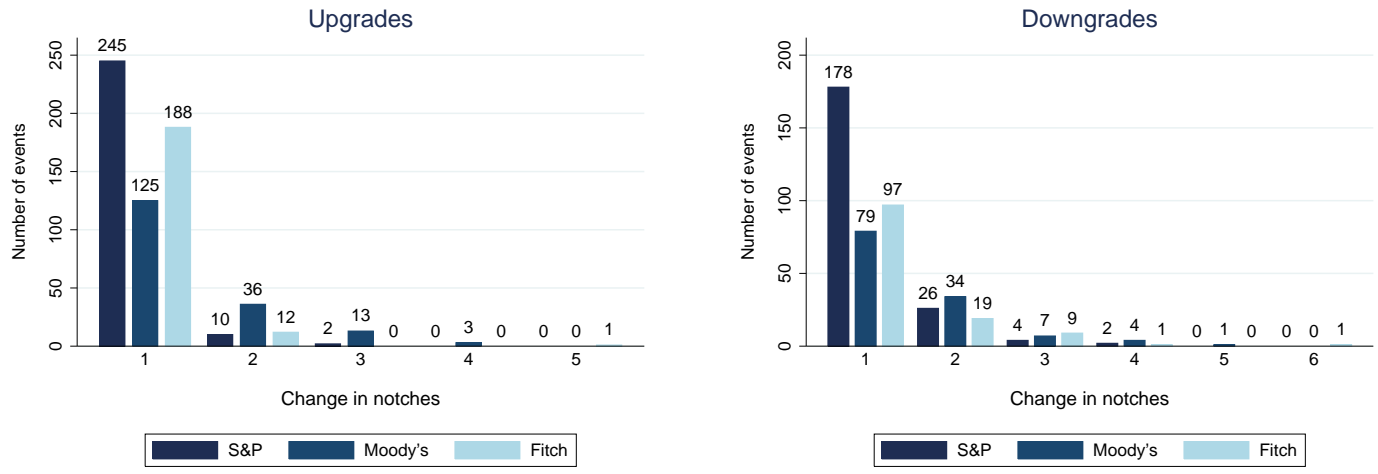

Notes - This figure shows the distribution of the severity of rating changes by agency, measured on a 17-notch scale. Numbers are based on the sample of 1,097 rating announcements (635 upgrades, 462 downgrades) made by S\&P, Moody's and Fitch between 1994 and 2011. 
Table A.1: Variable definitions

\begin{tabular}{|c|c|c|}
\hline Variable & Definition & Sources \\
\hline$\Delta$ Spread & $\begin{array}{l}\text { Change in the non-event country spread vis-à-vis US Treasuries of compa- } \\
\text { rable maturity over the two-trading-day window }[-1,+1] \text { around the rating } \\
\text { announcement (day } 0 \text { ), measured in percentage points. }\end{array}$ & $\begin{array}{l}\text { Bloomberg, Datast- } \\
\text { ream, JP Morgan, } \\
\text { US Department of } \\
\text { the Treasury }\end{array}$ \\
\hline$L A R G E$ & $\begin{array}{l}\text { Dummy variable taking on a value of one for "large" rating changes of two } \\
\text { notches or more; zero otherwise. Notches are measured on a linear 17-notch } \\
\text { scale. }\end{array}$ & S\&P, Moody's, Fitch \\
\hline InitRat & $\begin{array}{l}\text { Credit rating held by the event country with the announcing CRA prior to } \\
\text { the event, measured on the } 17 \text {-notch scale. }\end{array}$ & S\&P, Moody's, Fitch \\
\hline$\Delta$ InitRat & $\begin{array}{l}\text { Absolute difference between InitRat and the average of all credit ratings held } \\
\text { by the non-event country with the three CRAs, measured on the } 17 \text {-notch } \\
\text { scale. }\end{array}$ & S\&P, Moody's, Fitch \\
\hline OnWatch & $\begin{array}{l}\text { Dummy variable taking on a value of one if the event country was on watch, } \\
\text { or review, by the announcing CRA at the time of the event; zero otherwise. }\end{array}$ & S\&P, Moody's, Fitch \\
\hline SimActs WdwEvt & $\begin{array}{l}\text { Number of upgrade (downgrade) announcements made on the event country } \\
\text { by respective other CRAs over the two-week interval }[-14,-1] \text { (calendar days) } \\
\text { before the upgrade (downgrade) event. }\end{array}$ & S\&P, Moody's, Fitch \\
\hline SimActsDayNonEvt & $\begin{array}{l}\text { Number of upgrade (downgrade) announcements made on the non-event coun- } \\
\text { try by any CRA on the same day as the upgrade (downgrade) of the event } \\
\text { country. }\end{array}$ & S\&P, Moody's, Fitch \\
\hline$V I X$ & Volatility measure for the S\&P 500 stock market index in the United States. & Bloomberg \\
\hline
\end{tabular}


Region

TradeBloc

ExpImpEvt

CapOpen(Non)Evt
Dummy variable taking on a value of one if the event and non-event country belong to the same geographical region; zero otherwise.

Dummy variable taking on a value of one if the event and non-event country are members of a common major trade bloc; zero otherwise. The trade blocs are: EU, NAFTA, ASEAN, Mercosur, CARICOM, Andean Community, Gulf Cooperation Council, Southern African Customs Union, Economic Community of Central African States, Economic Community of West African States, Organisation of Eastern Caribbean States.

Importance of the event to the non-event country in terms of exports, measured as the non-event country's ratio of exports to the event country to domestic GDP.

De jure measure of the event (non-event) country's degree of capital account openness. Based on dummy variables, it codifies the restrictions on crossborder financial transactions reported in the IMF's Annual Report on Exchange Rate Arrangements and Exchange Restrictions.

SizeEvt Size of the event country, measured in logs of US dollar GDP.

$\Delta$ Size Size differential of the event over the non-event country, measured in logs of US dollar GDP.

$\Delta$ TrendGrowth Absolute difference between the event and non-event country's GDP trend growth, calculated for the sample period 1994-2011 on the basis of annual data using a Hodrick-Prescott filter with smoothing parameter 6.25.
CIA World Factbook

Authors' definition

World Bank

Chinn and Ito (2006)

World Bank

World Bank

World Bank 
Table A.2: Baseline regressions, downgrades — Robustness checks

\begin{tabular}{lccccc}
\hline \hline & Baseline & Ex notches $\geq 4$ & Ex notches $\geq 3$ & Crises & S\&P effect? \\
\hline LARGE & $0.0207^{* * *}$ & $0.0206^{* * *}$ & $0.0263^{* * *}$ & $0.0184^{* * *}$ & $0.0273^{* * *}$ \\
& $(0.0066)$ & $(0.0068)$ & $(0.0077)$ & $(0.0063)$ & $(0.0065)$ \\
InitRat & -0.0008 & -0.0020 & -0.0019 & -0.0006 & -0.0010 \\
& $(0.0017)$ & $(0.0018)$ & $(0.0019)$ & $(0.0017)$ & $(0.0017)$ \\
SInitRat & 0.0008 & 0.0007 & -0.0001 & 0.0008 & 0.0008 \\
& $(0.0009)$ & $(0.0009)$ & $(0.0009)$ & $(0.0009)$ & $(0.0009)$ \\
OnWatch & -0.0046 & -0.0026 & 0.0023 & -0.0048 & -0.0052 \\
& $(0.0054)$ & $(0.0056)$ & $(0.0059)$ & $(0.0055)$ & $(0.0054)$ \\
SimActsWdwEvt & $0.0141^{* *}$ & $0.0173^{* * *}$ & $0.0192^{* * *}$ & $0.0138^{* *}$ & $0.0140 * *$ \\
\multirow{3}{*}{ SimActsDayNonEvt } & $(0.0065)$ & $(0.0066)$ & $(0.0074)$ & $(0.0065)$ & $(0.0065)$ \\
& $0.1477^{* *}$ & $0.1540^{* *}$ & $0.1538^{* *}$ & $0.1472^{* *}$ & $0.1480^{* *}$ \\
VIX & $(0.0648)$ & $(0.0658)$ & $(0.0674)$ & $(0.0649)$ & $(0.0649)$ \\
& $0.0006^{*}$ & $0.0008^{* *}$ & $0.0008^{* *}$ & $0.0006^{*}$ & $0.0006^{*}$ \\
& $(0.0004)$ & $(0.0004)$ & $(0.0004)$ & $(0.0004)$ & $(0.0004)$
\end{tabular}

(continued on next page) 


\section{Baseline regressions, downgrades - Robustness checks (continued)}

\begin{tabular}{|c|c|c|c|c|c|}
\hline \multicolumn{3}{|l|}{ Euro $\times L A R G E$} & \multicolumn{3}{|c|}{$\begin{array}{c}0.0107 \\
(0.0118)\end{array}$} \\
\hline Asian $\times L A R G E$ & & & & $\begin{array}{c}0.0261 \\
(0.0395)\end{array}$ & \\
\hline$S B P \times L A R G E$ & & & & & $\begin{array}{c}-0.0234^{*} \\
(0.0128)\end{array}$ \\
\hline $\mathrm{N}$ & 21,931 & 21,519 & 20,510 & 21,931 & 21,931 \\
\hline Event countries & 84 & 84 & 84 & 84 & 84 \\
\hline Non-event countries & 73 & 73 & 73 & 73 & 73 \\
\hline Downgrades & 427 & 418 & 399 & 427 & 427 \\
\hline$R^{2}$ & 0.0423 & 0.0434 & 0.0437 & 0.0423 & 0.0425 \\
\hline
\end{tabular}

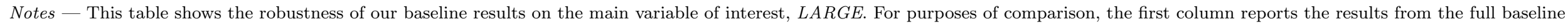

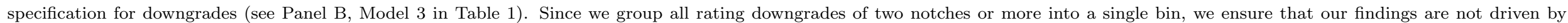

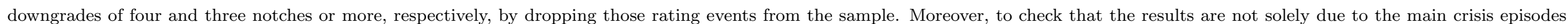

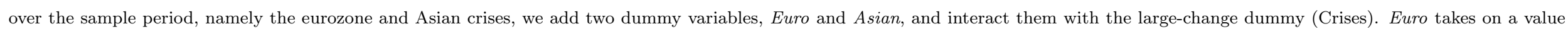

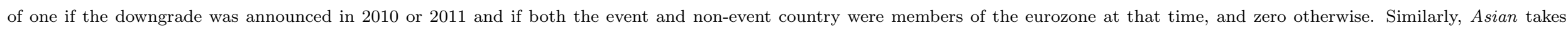
on a value of one for all downgrades between July 1997 and December 1998 in which both the event and the non-event country are from either of the following countries: Indonesia, Malaysia,

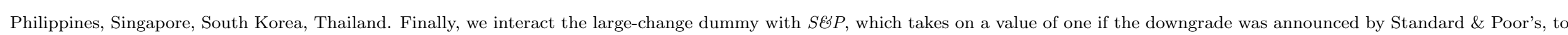
test whether this agency's relatively infrequent large downgrades account for our results. 